\title{
Temuan kista dentigerus rahang atas dengan perluasan kavum nasal dan sinus maksilaris melalui CBCT dan panoramik radiograf
}

\author{
Yohanes Hutasoit ${ }^{1}$, Belly Sam ${ }^{1}$, Ria Noerianingsih Firman ${ }^{1}$ \\ 'Departemen Radiologi Kedokteran Gigi, Fakultas Kedokteran Gigi Universitas Padjajaran, \\ Indonesia \\ *Korespondensi: papaluaman@amail.com \\ Submisi: 26 Juli 2018; Penerimaan: 28 November 2020; Publikasi online: 31 Agustus 2020 \\ DOI: $\underline{10.24198 / j k g . v 32 i 1.18013}$
}

\begin{abstract}
ABSTRAK
Pendahuluan: Kista dentigerous atau kista folikuler merupakan kista odontogenik yang terbentuk selama perkembangan gigi dan terbentuk karena akumulasi cairan di rongga folikuler pada gigi yang belum erupsi. Lokasi gigi-gigi yang sering berhubungan dengan kista dentigerous adalah gigi M3 rahang bawah, $\mathrm{C}$ rahang atas, $\mathrm{P}$ rahang bawah dan jarang pada gigi $\mathrm{M} 3$ rahang atas. Kista dentigerous yang berkaitan dengan gigi supernumerari dan sinus maksilaris sangat jarang ditemukan. Panoramik dan CBCT dapat dilakukan untuk melihat kasus kista dentigerous. Tujuan laporan kasus ini untuk melihat temuan kista dentigerous di rahang atas yang meluas sampai ke kavum nasi dan sinus maksilaris melalui gambaran CBCT dan panoramik radiograf. Laporan kasus: Seorang pasien laki-laki berusia 27 tahun datang ke RSGM Unpad untuk dilakukan CBCT-3D. Keluhan pasien yaitu bengkak di daerah langit-langit lebih dari 1 tahun yang lalu, bengkak meluas ke pipi sejak 1-2 bulan yang lalu. Keluhan bengkak tidak terasa nyeri. Konsistensi massa keras dan terasa nyeri saat ditekan. Hasil pemeriksaan CBCT dan histopatologi menyatakan bahwa lesi merupakan kista dentigerous. Simpulan: Kista dentigerous pada СВCT menunjukkan perluasan lesi ke kavum nasal dan sinus maksilaris serta tepi yang lebih jelas dibandingkan dengan radiograf panoramik.
\end{abstract}

Kata kunci: $\mathrm{CBCT}$, panoramik, kista dentigerous, kavum nasal, sinus maksilaris.

\section{Maxillary dentigerous cyst finding with expansion of the nasal cavity and maxillary sinus through the CBCT and panoramic radiographs}

\begin{abstract}
Introduction: Dentigerous cysts or follicular cysts are odontogenic cysts that form during tooth development and formed from the accumulation of fluid in the follicular cavity of an unerupted tooth. The teeth locations often associated with dentigerous cysts are the mandibular M3, the maxillary $C$, the mandibular $P$, and rarely occurred in the maxillary M3. Dentigerous cysts associated with supernumerary teeth and maxillary sinuses are extremely rare. Panoramic and CBCT can be performed to observe dentigerous cysts cases. This case report was aimed to examine the findings of a maxillary dentigerous cyst with expansion of the nasal cavity and maxillary sinus through CBCT and panoramic radiographs. Case report: A 27-yearsold male patient came to Universitas Padjadjaran Dental Hospital for CBCT-3D examination. The patient's complaint was swelling in the palate from more than one-year prior, extended to the cheek from 1-2 months prior. Complaints of swelling was not painful, although, when pressed, then a solid, painful mass will be felt. The results of CBCT and histopathological examination confirmed that the lesion was a dentigerous cyst. Conclusion: Dentigerous cyst on CBCT showed expansion of the lesion to the nasal cavity and maxillary sinus as well as more apparent margins compared to panoramic radiographs.
\end{abstract}

Keywords: $C B C T$, panoramic, dentigerous cyst, nasal cavity, maxillary sinus. 


\section{PENDAHULUAN}

Kista dentigerus atau kista folikular merupakan lesi yang sering terjadi pada daerah maksila dan mandibula dengan persentase 20$24 \%$ dari seluruh kista pada rahang setelah kista radikuler. Kista dentigerus merupakan lesi patologis berupa rongga, dilapisi oleh epitel yang mengelilingi mahkota gigi dari cemento enamel junction (CEJ) dan berisi cairan pada gigi yang belum erupsi. ${ }^{1,2,3,4}$ Lesi ini dapat ditemukan pada anak-anak maupun dewasa dengan insiden tertinggi pada dekade ketiga kehidupan dengan rasio laki-laki berbanding wanita 1,6:1 tanpa adanya predileksi rasial..$^{2,4,5} \mathrm{Gigi}$ molar ketiga rahang bawah, kaninus rahang atas, dan premolar rahang bawah merupakan gigi yang sering mengalami kista dentigerus. Kista ini sangat jarang ditemukan pada keadaan odontoma, dan gigi supernumerari yang tidak erupsi. ${ }^{4}$

Gigimesioden merupakan gigisupernumerari yang terletak pada daerah insisif sentral rahang atas dengan prevalensi $0,15 \%$ sampai $1,9 \%$. Gigi mesioden sering mengakibatkan permasalahan lainnya seperti terjadinya diastema pada bagian median, terhambatnya erupsi gigi insisif sentral, terganggunya posisi gigi insisif sentral dan terbentuknya kista dentigerus. Kejadian kista dentigerus pada gigi supernumerari sebesar $5-6 \%$ dari semua kasus kista dentigerus. ${ }^{4}$
Radiografi panoramik merupakan radiografi dua dimensi yang rutin dilakukan di bidang kedokteran gigi untuk membantu menegakkan radiodiagnosis. Panoramik radiograf menampilkan gambaran dua dimensi sehingga terkadang mengakibatkan keraguan dalam menentukkan radiodiagnosis. Penggunaan radiograf CBCT dengan gambaran tiga dimensi (3D) mampu memberikan gambaran yang lebih detail yang membantu dalam menegakkan radiodiagnosis. ${ }^{5}$ Tujuan laporan kasus ini untuk melihat gambaran kista dentigerus di rahang atas yang meluas sampai ke kavum nasi dan sinus maksilaris melalui gambaran CBCT dan panoramik radiograf.

\section{LAPORAN KASUS}

Seorang pasien laki-laki berusia 27 tahun datang ke RSGM UNPAD dirujuk oleh dokter spesialis bedah mulut untuk dilakukan pemeriksaan CBCT-3D. Pasien mengeluh adanya pembengkakan pada daerah palatum lebih dari 1 tahun yang lalu. Keluhan bengkak tidak terasa nyeri. Konsistensi massa keras dan terasa nyeri saat ditekan. Pembengkakan pada palatum berukuran lebih kurang $2 \times 2 \mathrm{~cm}$. Mukosa palatum tampak normal (Gambar 1 C,D dan E). Pasien tidak mengeluhkan adanya perubahan kesimetrisan wajah (Gambar 2 a dan b). Tidak
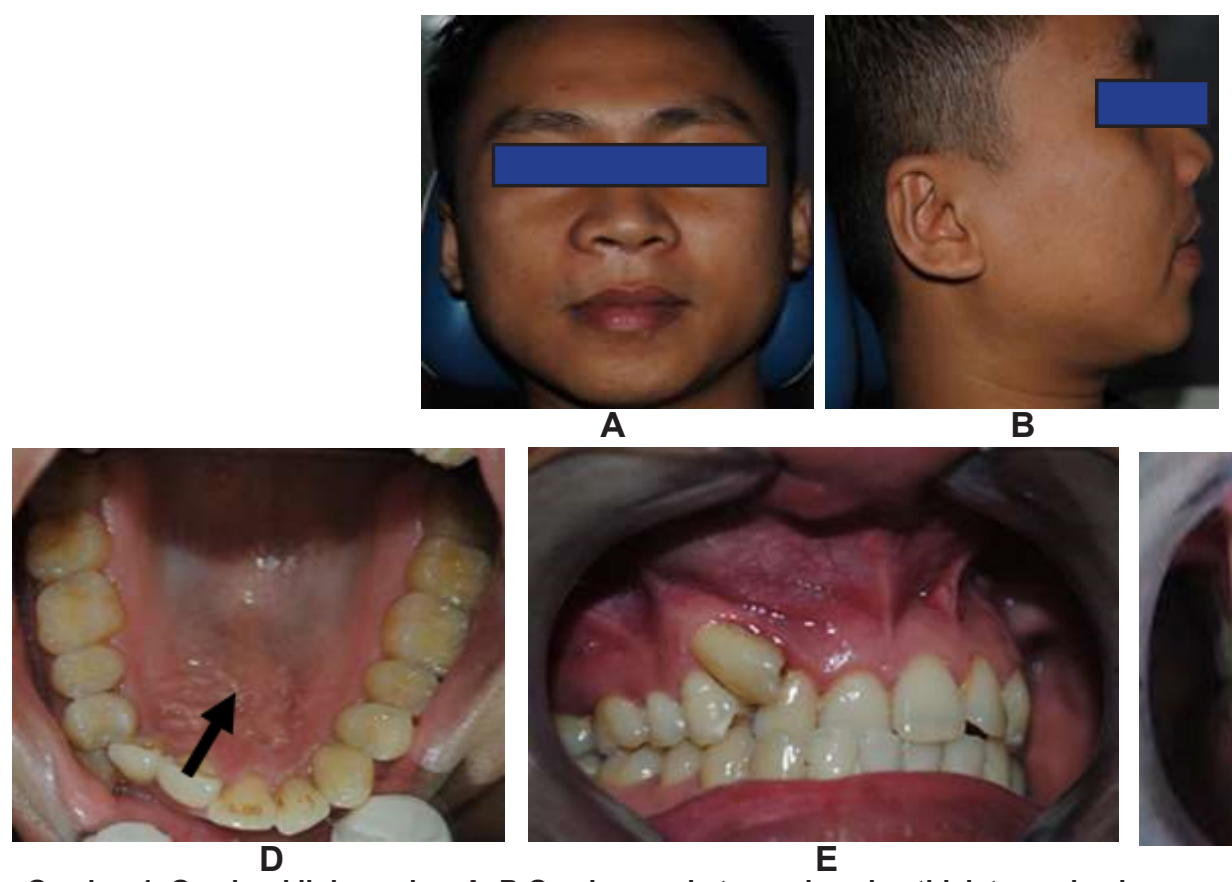

A

B
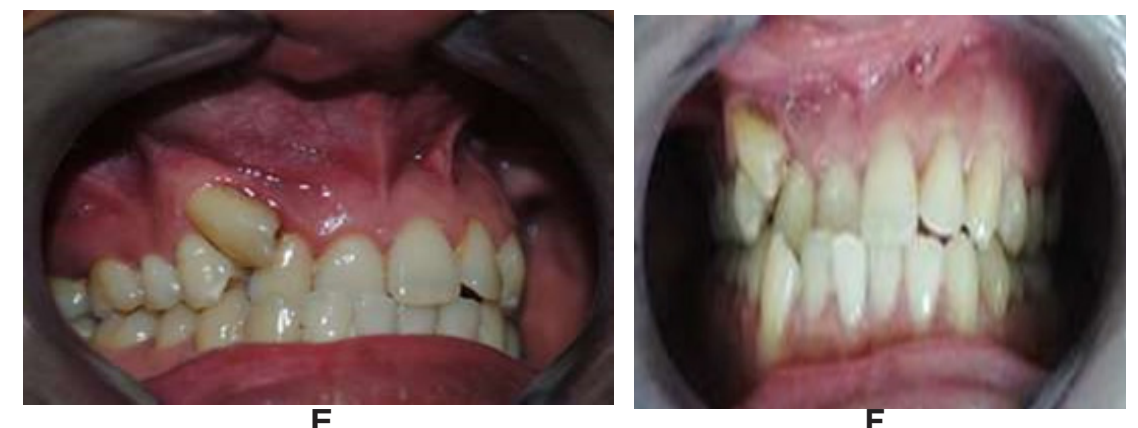

Gambar 1. Gambar klinis pasien. A, B Gambaran ekstra oral pasien tidak tampak adanya pembengkakan pada ekstraoral pasien; C, D, E Gambaran intraoral pasien terlihat adanya pembengkakan pada palatum pasien (tanda panah).

(Sumber: Dokumentasi sendiri) 


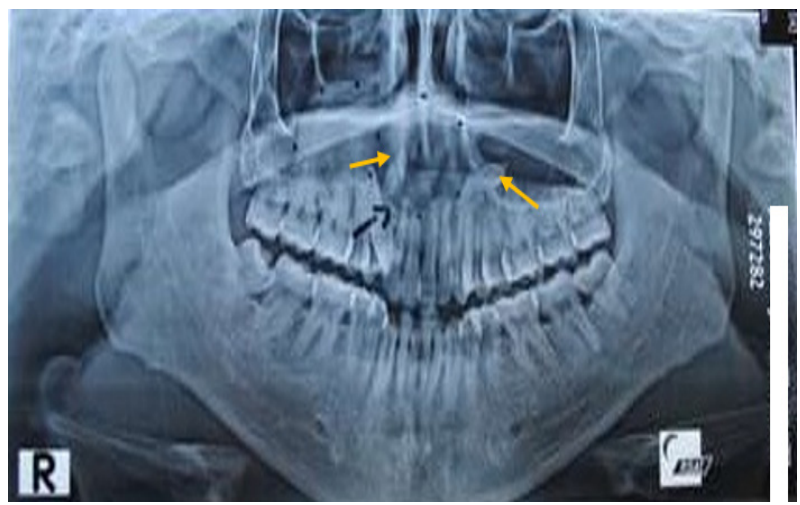

Gambar 2. Foto panoramik pasien memperlihatkan lesi radiolusen berbatas well defined pada regio insisif sentral yang meluas sinus maksilaris dextra (tanda panah hitam). Tampak 2 gigi mesiodens yang impaksi dengan posisi terbalik (tanda panah kuning), tampak pula gigi 13 yang mengalami malposisi. Pada foto panoramik gambaran resopsi pada gigi 11 tidak dapat terlihat. (Sumber: Dokumentasi sendiri)
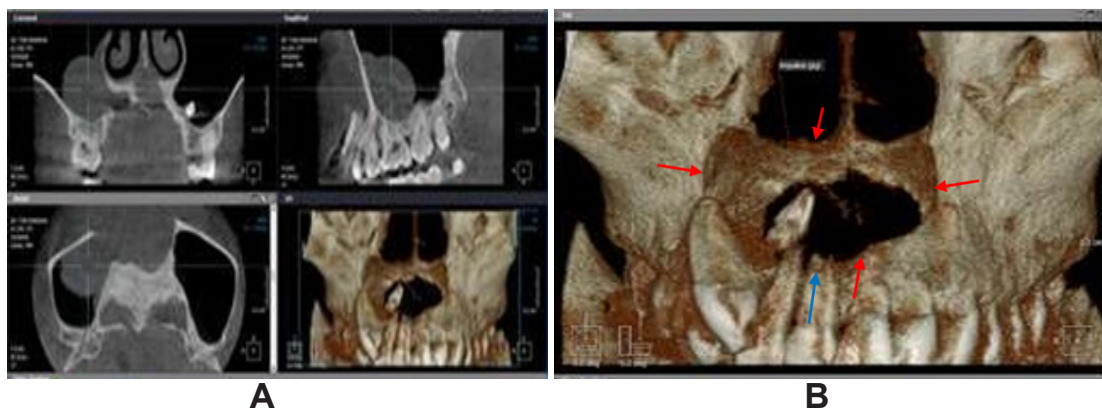

B

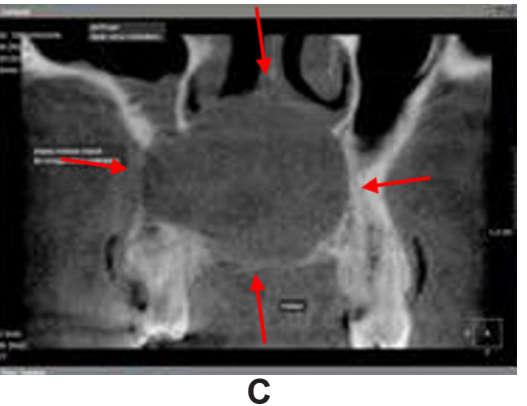

Gambar 3. Gambaran СВСТ lesi kista dentigerus pasien, A. gambaran MPR view (Multi Planar Reconstruction); B.

Gambaran frontal; C. Gambaran 3D. Terlihat gambaran dan perluasan lesi tampak lebih jelas yang meluas ke dasar kavum nasal dan sinus maksilaris sinistra (tanda panas merah), terlihat gigi supernumerari yang impaksi dengan mahkota yang terbalik dan tampak ujung akar gigi insisif sentral mengalami resopsi eksternal yang pada foto panoramik tidak terlihat (tanda panah biru). (Sumber: Dokumentasi sendiri)

ada riwayat demam. Pasien belum mengonsumsi obat dan belum mendapatkan tindakan apapun. Gambaran radiografi panoramik memperlihatkan lesi radiolusen well defined pada regio insisif sentral maksila disertai gambaran radiopak menyerupai gigi yang diketahui sebagai gigi supernumerari yang impaksi (gambar 2). Pemeriksaan CBCT dilakukan dengan menggunakan Vatech PicassoTrio 3D Dental Imaging untuk melihat perluasan lesi dan gambaran yang lebih spesifik dari lesi tersebut. Pada pemeriksaan CBCT, terlihat gambaran lesi dengan luas $3 \mathrm{~cm}$ yang meluas hingga kavum nasal dan sinus maksilaris dextra. Lesi merupakan lesi tunggal dengan batas well defined terkortikasi. Lesi menyebabkan resopsi akar gigi 11 , migrasi gigi supernumerari dan menekan gigi kaninus sehingga posisinya menjadi mesioversi (Gambar 3).

Tindakan pembedahan dilakukan untuk pengangkatan lesi dan dilakukan pemeriksaan histopatologi dengan diagnosis kista dentigerus. Hal ini sesuai dengan gambaran padai radiograf $\mathrm{CBCT}$ dan juga panoramik. Pasien menyetujui kasusnya untuk dipublikasikan dengan menandatangani informed consent.

\section{PEMBAHASAN}

Kara $\mathrm{dkk}^{6}$ menyatakan bahwa kista dentigerus terjadi pada gigi impaksi dan terkadang berkaitan dengan sinus maksilaris, kondisi ini merupakan hal yang sangat jarang ditemukan. Buyukkurt MC $\mathrm{dkk}^{7}$ dalam penelitian survey tentang keterlibatan kista dentigerus terhadap sinus maksilaris membuktikan bahwa selama 30 tahun (1980-2010) hanya terdapat 17 kasus. Dalam penelitian lain dikatakan bahwa kista dentigerus terkadang ditemukan secara tidak sengaja pada pemeriksaan panoramik radiograf. ${ }^{8,9}$

Radiograf panoramik sangat berguna untuk mengidentifikasi dan menegakkan radiodiagnosis dari kista dentigerus, namun memiliki beberapa kekurangan. Kekurangnnya dalam kasus ini yaitu kurang mampu memperlihatkan hubungan lesi dengan struktur anatomi yang berdekatan, selain 
itu lesi juga terdapat pada area anterior rahang atas yang sering kali superimposisi sehingga memberikan gambaran tidak jelas, terlebih untuk kasus ini perluasan lesi kearah superior dan posterior tidak terlihat. Kelemahan lainnya adalah modalitas dua dimensi tidak dapat mengidentifikasi dengan tepat suatu lesi sehingga rencana perawatan dapat menjadi tidak tepat pula. ${ }^{5,10}$ Gambaran panoramik pada kasus ini tidak dapat memperlihatkan karekteristik spesifik dari kista dentigerus dan juga perluasan lesi yang sulit untuk diidentifikasi sehingga dibutuhkan pemeriksaan dengan modalitas CBCT.

CBCT telah digunakan secara luas di bidang kedokteran gigi untuk mendapatkan informasi pada struktur gigi dan maksilofasial untuk tujuan diagnosis dan rencana pembedahan. Cha dkk ${ }^{11}$ menjelaskan bahwa penggunaan $\mathrm{CBCT}$, dapat membantu dalam penegakkan diagnosis dan rencana perawatan. Keuntungan penggunaan CBCT adalah dapat melihat batas lesi pada jaringan keras.

Keuntungan yang penting lainnya adalah lesi dapat dilihat dari berbagai bidang (axial, coronal, dan sagital) karena gambar disusun secara MPR untuk melihat adanya resorpsi tulang, tulang sklerosis, ekspansi dari lesi ke arah daerah yang vital, sehingga dokter bedah mulut dapat melakukan tindakan operasi dengan mempertimbangkan akses yang tepat terhadap struktur vital lain di daerah rahang. Gambaran CBCT pada kasus ini memperlihatkan adanya perluasan lesi ke kavum nasal dan sinus maksilaris sinistra, posisi gigi supernumerari yang impaksi serta resorpsi eksternal pada akar gigi insisif sentral kanan yang tidak terlihat pada gambaran panoramik. ${ }^{12}$

CBCT memiliki dosis radiasi yang lebih besar dibandingkan panoramik, namun pada pemeriksaan panoramik yang dilakukan tidak dapat menggambarkan perluasan lesi secara detail (3 dimensi) selain itu pemeriksaan panoramik tidak dapat memperlihatkan tanda-tanda spesifik dari lesi seperti pada kasus. CBCT memiliki keuntungan yang lebih baik dibandingkan panoramik. Hal ini sesuai dengan dengan prinsip ALARA dimana penegakkan diagnosis akan menjadi lebih baik dan menghindari pemotretan berulang yang tidak diperlukan akibat gambaran yang tidak dapat diinterpretasi. Pemeriksaan CBCT juga penting untuk dilakukan setelah pengangkatan kista dentigerus untuk dapat melihat penyembuhan tulang atau adanya pertumbuhan lesi yang baru pada lokasi kista. ${ }^{6,13}$

Kista dentigerus merupakan kista odontogenik yang berhubungan dengan gigi impaksi. Kista dentigerus pada kasus ini memiliki batas jelas dengan konten isi radiolusen, akan tetapi dari literature dikatakan bahwa batas kista yang menembus kavum nasal ataupun sinus maksilaris tidak memiliki batas yang jelas, karena tidak memiliki struktur tulang pada anatominya. Hal ini berbeda pada kasus yang ditemukan dimana batas lesi terlihat jelas dan terkortikasi, kondisi ini membuktikan bahwa lesi berasal dari rahang atas yang meluas sampai kavum nasal dan sinus maksilaris. ${ }^{14}$

\section{SIMPULAN}

Kista dentigerus pada СВCT menunjukkan perluasan lesi ke kavum nasal dan sinus maksilaris serta tepi yang lebih jelas dibandingkan dengan radiograf panoramik.

\section{DAFTAR PUSTAKA}

1. Sindi AM. Bilateral Mandibular Dentigerous Cysts Presenting as an Incidental Finding: A Case Report. Am J Case Rep. 2019 Aug 5;20:1148-1151. DOI: 10.12659/AJCR.917943.

2. Aggawal P, Sohal BS, Uppal KS. Dentigerus Cyst of Mandible. Int $\mathrm{J}$ Head and Neck Surgery. 2013; vol. 2: 95-97. DOI: 5005/jpjournals-10001-1149

3. Anjana G, Varma B, Ushus P. Management of dentigerus Cyst: A Two-Year Review. Int J Clin Ped Dent. 2011; 4(2): 147-151. DOI: $10.5005 /$ jp-journals-10005-1100

4. Shah KM, Karagir A, Adaki S, Pattanshetti C. Dentigerus cyst associated with an impacted anterior maxillary supernumerary tooth. BMJ Case Rep. 2013. p. 1-3. DOI: $10.1136 / \mathrm{bcr}-$ 2012-008329

5. Deana NF, Alves N. Cone Beam CT in Diagnosis and Surgical Planning of dentigerus Cyst. Hindawi Publishing Corporation. 2017; 1-5 DOI: $10.1155 / 2017 / 7956041$

6. Kara MI, Yanik S, Altan A, Oznalcin O, Ay S. Large dentigerous cyst in the maxillary sinus leading to diplopia and nasal obstruction: case 
report. J Istanb Univ Fac Dent. 2015. 29;49(2): 46-50. DOI: 10.17096/jiufd.10506.

7. Buyukkurt MC, Omezli MM, Miloglu O. dentigerus cyst associated with an ectopic tooth in the maxillary sinus: a report of 3 cases and review of the literature. Oral Surg Oral Med Oral Pathol Oral Radiol Endod. 2010; 109: 6771. DOI: 10.1016/j.joms.2006.02.033

8. Sindi AM. Bilateral Mandibular Dentigerous Cysts Presenting as an Incidental Finding: A Case Report. Am J Case Rep. 2019 Aug 5;20:1148-1151. DOI: 10.12659/AJCR.917943.

9. Krishnamoorthy B, Bhai P. Diagnostic CBCT in Dentigerous Cyst with Ectopic Third Molar in the Maxillary Sinus-A Case Report. J Clin Diagn Res. 2014; 8(6): ZD07-9. DOI: $10.7860 /$ JCDR/2014/8414.4469.

10. Vidya L, Ranganathan K, Praveen B, Gunaseelan R, Shanmugasundaram S. Cone-beam computed tomography in the management of dentigerus cyst of the jaws: $A$ report of two cases. Indian J Radiol Imaging. 2013; 23(4): 342-346. DOI: 10.4103/09713026.125614

11. Khojastepour L, Haghani J, Mirbeigi S, Incidental dentomaxillofacial findings on cone beam computed tomography images of Iranian population. J Oral Health Oral Epidemiol. 2014; 3(1): 12-15.

12. Martinelli-Kläy CP, Martinelli $C R$, Martinelli $C$, Macedo HR, Lombardi T. Unusual Imaging Features of Dentigerous Cyst: A Case Report. Dent J (Basel). 2019. 1;7(3):76. DOI: 10.3390/ dj7030076.

13. Meng $Y$, Zhao YN, Zhang YQ, Liu DG, Gao $Y$. Three-dimensional radiographic features of ameloblastoma and cystic lesions in the maxilla. Dentomaxillofac Radiol. 2019; 48(6): 20190066. DOI: 10.1259/dmfr.20190066.

14. White SC, Pharoah MJ. Oral Radiology Principle and Interpretation. $7^{\text {th }}$ ed. Missouri: Mosby. 2014; p.338 